\title{
O MÉTOdo DiNHEIRO NA ECONOMIA DA FILOSOFIA DO DINHEIRO
}

Francisco Felizol Marques

(Centro de Filosofia da Universidade de Lisboa)

\section{$\mathrm{O}$ relativismo}

A introduzir a sua tradução inglesa da Filosofia do Dinheiro (1900), Frisby, perante a atordoante diversidade de temas ali tratados, trata a questão metodológica como algo, no mínimo, secundário para Simmel ${ }^{1}$. Muito improvável seria que filosofia com dinheiro dispensasse qualquer cuidado metodológico. Pelo contrário, a Filosofia do Dinheiro propõe uma nova epistemologia, o relativismo; e o dinheiro, longe de ser objecto, é materialização, prolongamento, método da sua proposta epistemológica.

Antes de começar a descrever essa proposta epistemológica presente na Filosofia do Dinheiro, importa chamar a atenção para a sua colocação: ali ao início da obra, logo após tratar do valor e da troca e mesmo antes de tratar do dinheiro. Esta disposição, à partida desconcertante, pois esperar-se-ia que ao valor e à troca imediatamente se seguisse o dinheiro, requer já atenção. Ou esta arrumação confirma uma desarrumação anti-metodológica, ou esta aparente desarrumação indicia outro tipo de arrumação metodológica. Mas siga-se a essa epistemologia.

Rejeitando quaisquer laivos de positivismo, Simmel concebe o conhecimento, incluindo a região dita científica, como discreto e fragmentário; perpassado, mesmo, por uma rede de cruzamentos e ligações invisíveis para a consagrada disposição em ramos científicos. Porque ao homem repugna assentar na instabilidade, experimentada como insegura, de um fluxo corrente e imprevisível, tem necessidade de assentar, de se fundar numa estância estável. Uma epistemologia que funda a ciência em fundamento, quer, garantindo-se de certeza e continuidade, garantir ao

\footnotetext{
${ }^{1}$ «Simmel himself saw the preocupation with methodology as a kind of fetishism and took method to be somewhat akin to style in art.» David Frisby, Introduction, in Georg Simmel, Philosophy of Money, Routledge, p. 7.
}

Philosophica, 42, Lisboa, 2013, pp. 77-91. 
homem certeza com continuidade. Em obras posteriores Simmel desenvolverá esta demanda de permanência imortal que, das pirâmides tumulares egípcias e das flechas "imóveis" de Zenão ${ }^{2}$, se continuará pelo conceito de substância ${ }^{3}$, modo de garantir um eterno "sub" onde possa assentar um estável estante para o homem e para seu conhecimento. Simmel detecta a mesma obsessão de fundar em ponto fixo para fundamentar certezas, tanto pela história da filosofia como no conhecimento elevado a científico. O problema é que este fundar fundamentador expõe a ciência aos ataques do cepticismo, ao invés de garantir essa estabilidade e segurança que aparenta.

Mal se assenta a ciência em princípios fundadores quando estes são pré-condições artificiais ${ }^{4}$, são ideais pré-concebidos, verdades fixadas e fraccionadas, (des)continuamente pontuais ${ }^{5}$. Assenta então o conhecimento numa última ou primeira verdade que, por demonstrar e provar, (su)posto tomado por fundamento, assim se mantém até nova verdade fundamento a destronar ${ }^{6}$. Uma ânsia de permanências fundada e confiada numa substância fixa e desconhecida é simplificação ingénua. Esta epistemologia da substância, por vezes excitada a absolutismo epistemológico, é tique ou mania de fundamento. Como naquela fábula popularizada por William James, onde os antigos hindus faziam o mundo assentar no dorso de quatro elefantes, quais, por sua vez, assentavam numa carapaça de tartaruga, a carapaça fundamento, a querer suportar toda a ciência, arrisca afundá-la, deixa-a vulnerável a contradições, provoca, senão invoca, ataques cépticos.

A impossibilidade de fundamento fixo começa logo para Simmel na questão da verdade. Havendo «tantas verdades diferentes como diferentes organizações e condições de vida» ${ }^{7}$, «a verdade é um conceito relacio-

${ }^{2}$ Georg Simmel, Hauptprobleme der Philosophie, Gesamtausgabe (GSG), Band 14, p. 65.

${ }^{3}$ Para Simmel, esta ânsia da estabilidade a conferir certeza e permanência é grande preocupação da filosofia grega retomada pela Idade Moderna na substância de Espinosa. (Simmel, GSG 14, pp. 52-54).

${ }^{4}$ Simmel, Philosophie des Geldes, GSG 6, p. 9.

${ }^{5}$ Simmel vê as desvantagens desta descontinuada interpretação do mundo. Ela quebrou a visão mitológica que assegurava a integração dos nossos impulsos, emoções, preocupações (Simmel, GSG 6, p. 662). Muitas das tensões psicológicas e sociais do mundo moderno encontram mesmo origem nesta quebra. E isto agrava-se quando a conquista tecnológica de um detalhe, de vários detalhes, faz o homem moderno extrapolar, pretender daí dar fundamento a todas as partes. Simmel, GSG 6, p. 671.

${ }^{6}$ Simmel, GSG 6, p. 98,99.

${ }^{7}$ Simmel, GSG 6, p. 102. 
nal» ${ }^{8}$. Uma diferente constituição, outra percepção de espaço, outra organização mental, outras necessidades, e o homem poderia dispensar a lei posta na gravidade ${ }^{9}$. A verdade vai sempre em relação; a atracção dessa terra sobre a maçã, não nos pode livrar de conceber a atracção da maçã sobre essa terra ${ }^{10}$. Não se livra esta verdade em Simmel, apontada à utilidade, à acção para consequências úteis que nos permitam sobreviver, de um inegável legado pragmatista ${ }^{11}$. E quando é a selecção útil das representações, conformada à acção prática necessária a nosso modo de vida, que nos faz dar unidade a um objecto, já se vislumbra o modo de Simmel livrar a subjectividade de ser subjectiva. Podendo esta verdade relacional imediatamente aparentar um exílio de toda a objectividade, não se pode simplificadamente rotular como subjectividade arbitrária. $\mathrm{O}$ conhecimento de um sujeito vale por ser o conhecimento útil, o conhecimento objectivo para a irrepetibilidade da sua forma de vida ${ }^{12}$.

Faz-se então o conhecimento duma inter-relação, duma fluidez que determina sujeito e objecto, sujeito com objecto. Inconcebível o conhecimento sem o outro, sem um eu aqui se consciencializar com o outro ali. Entre a vida interior e a exterior caem limites e absolutos: uma contínua relação, uma recíproca dependência, uma co-representação fazem-nas unidade mútua. A querela entre materialismo e idealismo perde sentido. «A mente é um produto do mundo como o mundo é um produto da mente ${ }^{13}$. Esse interior feito produto ou produtor do exterior dá lugar à reciprocidade, à mutualidade, à ponte entre mundo e consciência.

Sendo assim, na impossibilidade de se provar fundamento para a verdade, só «a reciprocidade das provas é a base do conhecimento concebido na sua perfeição» pelo que, desistindo de carapaças, «é lícito que a nossa imagem do mundo flutue no ar, quando o próprio mundo o faz» ${ }^{14}$. Que seja, esta (não) forma da realidade, ao invés da nossa ânsia de segurança e permanência, a "enformar" o nosso conhecimento. A "base" é essa temida instabilidade, essa relacionalidade circular dos conteúdos do conhecimento, onde qualquer conteúdo se refere a todos os outros, onde todos os conteúdos fluem num infinito aperfeiçoar nunca feito, nunca perfeito, jamais solvido ${ }^{15}$. A substância dá lugar à circunstância: cada

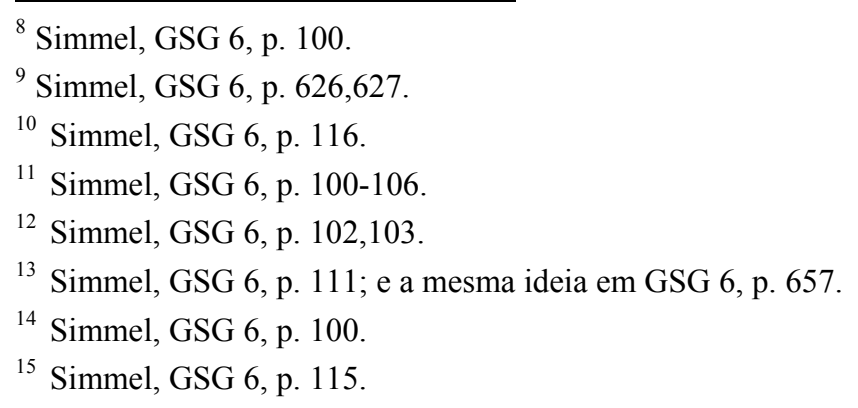


humilde ponto, prova, ou lei do conhecimento é, desafiando arqueologias e teleologias, princípio e fim, funda e é fundado por todos os outros pontos, provas ou leis. Nesta relacionalidade dinâmica, todo o saber e criação se abarca assim de sentido valendo e dependendo dos outros saberes e criações. Assim circunstancializado, não petrificado, o saber avança relacionalmente de uma posição circunstanciada a outra posição circunstanciada sem nunca se desligar dos conhecimentos que engloba, da sua circunstância. Caiam assim essências, substâncias, princípios constitutivos mais todo o castelo epistemológico de certezas vulnerável a contradições. Lugar aos princípios regulativos dum sistema aberto, dum não sistema em permanente mutação onde a contradição se complementa e assimila na circularidade e circunstância das diferentes perspectivas. Uma epistemologia assim, já implicitamente orgânica nas suas características, pode acompanhar a mudança e a transformação. Sem sistema a tolhê-la, esta verdade é destruidora de petrificações, é flexível de aceitar, integrar e absorver essas contradições, essas frestas vulneráveis a consequentes investidas cépticas.

A relatividade da verdade despe-a de absolutos; ela, e assim o conhecimento, é infinitamente «parcial e corrigível»" ${ }^{16}$, permanentemente aberta e provisória na sua contínua direcção ao absoluto nunca atingível. À maneira do dever-ser em Kant ou do eu absoluto depois em Fichte, imagine-se este conhecimento em Simmel como uma esfera nunca livre de arestas, nunca perfeita num perímetro, um limite assimptótico infinitamente aproximável, mas nunca alcançável. O progredir deste conhecimento é um permanente ligar descontínuo dos pontos de uma continuidade nunca alcançável; é um permanente aperfeiçoar, corrigir e mudar nunca perfeito. E porque «a conexão lógica entre dois conceitos reduz a distância entre eles mas não acaba com a descontinuidade» ${ }^{17}$, este progredir é um permanente reduzir distâncias, um encontrar novo ponto de entremeio onde se ligavam dois, um permanente suavizar dos ângulos na boa angústia de encontrar sempre novas arestas ou descontinuidades. Poderá parecer frustrante que sempre entre duas descontinuidades circunstancialmente postas como conhecidas jaza um vazio infinito, um infinito desconhecido entre dois pontos. $\mathrm{O}$ absoluto antes posto como princípio a fundar muda-se agora para um fim sempre acolá que, em nosso contínuo progredir, em nossa contínua descontinuidade, jamais alcançamos. Mas tanto o não fundamento como esse vazio em que repetidamente se tropeça, dão sobrevivência e continuidade a este avançar.

A "utilidade" desta utilidade pragmatista está precisamente em fundar por não fundar, por não assentar em substância ou fundamento artifi-

\footnotetext{
${ }^{16}$ Simmel, GSG 6, p. 116.

${ }^{17}$ Simmel, GSG 6, p. 114.
} 
cial. Esse abrigo da substância, do fundamento absoluto, obriga a petrificar permanências ${ }^{18}$, desabriga dos ataques do cepticismo. Ao invés, este relativismo orgânico, de que Simmel pretende imunizar a ciência ${ }^{19}$, é até capaz de se fortalecer com esse cepticismo.

Simmel, ciente das imediatas associações cépticas do termo "relativismo" (Relativismus), trata de convenientemente demarcar o seu relativismo, visando o progredir contínuo a um absoluto nunca alcançável mas sempre lá, da posição céptica negadora do absoluto. A relativização, o negar fundação em absolutos, aparente concessão ao cepticismo, visa precisamente desarmar o cepticismo. Por isso pode dizer:

A relatividade não significa, como vulgarmente se pensa, diminuição da verdade [...], mas pelo contrário, a realização e validação positivas do conceito de verdade. ${ }^{20}$

Sem negar o absoluto, sem cair a cepticismo, o relativismo dá à ciência por onde avançar, por esse absoluto arredado para limite assimptótico. Sem jazer nesse absoluto em forma de substâncias, fundamentos ou outras fantasmagóricas petrificações, a ciência, assim relativizada, priva o cepticismo de seu material combustível, enquanto se reforça duma autonomia de se julgar, provar, suportar a si mesma. É este relativismo de não fundar, este fundar na relação, que livra a ciência de se afundar. É ele que dá ao conhecimento uma relacionalidade, mutável e circunstancial mais consentânea com a "forma" da realidade.

E esta epistemologia da reciprocidade já leva muito da posterior ontologia simmeliana. Aí, o homem será ser intermediário, individualidade; aí, o homem não é nem está; antes vai; vai península, vai ponte ${ }^{21}$, vai pescoço $^{22}$, vai individualidade. $\mathrm{O}$ homem será ou um entre-ser, ou um entre-ir, ou um entre fazer-se sempre entre sua móvel e contínua subjecti-

${ }^{18}$ Nesta repulsa às permanências, poderá estar a chave da despreocupação de Simmel para com uma sua permanência materializada no deixar escola ou deixar discípulos. «Je sais que je mourrai sans héritier spirituel, et c'est bien ainsi. Mon héritage est semblable à une succession en argent liquide, répartie entre de nombreux descendants chacun place sa parte dans une acquisition particulière correspondant à sa propre nature, et dans laquelle il est impossible de reconnaitre l'héritage dont elle provient» (François Leger, La pensée de Georg Simmel. Contribution à l'histoire des idées en Allemagne au début du XXe siècle, Editions Kime 1989, pp. 14-15).

19 Simmel, GSG 6, p. 117.

${ }^{20}$ Simmel, GSG 6, p. 116. Acerca da demarcação entre relativismo e cepticismo ver Simmel, GSG 6, p. 97,98,117.

${ }^{21}$ Em Simmel, Brücke und Tür, 1907, GSG, 12, 55-61.

${ }^{22}$ Em Die ästhetische Bedeutung des Gesichts, 1901, GSG, 7, 36-48. 
vidade insular e indivídua (do indivíduo) e a tendencialmente mais fixa e imóvel objectividade continente do(s) outro(s). Tão impossível é então a nossa individualidade peninsular apartar-se desse continente, apartar-se do outro, mutilando-se em indivíduo, como abdicar da sua ilha, da sua intimidade, mutilando-se em universal. Essa epistemologia relativista, a viver de uma interacção contínua e aberta entre consciência e mundo, sujeito e objecto, é já de si inevitavelmente ontológica, já "vive" nesta ontologia posteriormente formalizada. Essa reciprocidade do conhecimento determina e é determinada pela reciprocidade do ser. Em Simmel, a reciprocidade não só se prolongará do conhecimento ao ser como se estabelecerá a conciliar conhecimento e ser: reciprocidade do conhecimento, reciprocidade do ser, reciprocidade entre conhecimento e ser.

É com esta epistemologia apresentada na Filosofia do Dinheiro, é com esta verdade relação, onde os conteúdos, nunca isolada ou absolutamente, valem relativa e circunstancialmente a outros, que Simmel tratará nesta como em posteriores obras as mais desconcertantemente variadas questões. Quando um qualquer conteúdo particular de conhecimento é ponto de e a todos os outros, terão de cair verdades (su)postas, tidas por estanques. Numa circularidade já antevista por Hegel ${ }^{23}$, qualquer coutada científica remete a todas as outras. A economia não o é sem a história, a psicologia, a religião, sem o todo que a engloba e condiciona e nem esse todo se pode completar sem economia, história, psicologia, religião. Simmel está convencido que todos os fenómenos, rotulados em arrumadas divisórias científicas, têm raízes subterrâneas a ligá-los, impossíveis de estancar por estas simplificações. Pois é através da relacionalidade do dinheiro que Simmel pretende nesta obra descobrir essas raízes e suas interligações.

\section{O método dinheiro}

Simmel começa por avisar no prefácio da Filosofia do Dinheiro, que «duas pessoas trocarem os seus produtos de modo algum é apenas um facto económico» ${ }^{24}$. Onde acaba a ciência, parte a filosofia a tentar dar coesão: a Filosofia do Dinheiro parte daquelas pré-condições por provar onde se finda a "exactidão científica" pelo que esta obra terá de continuamente transgredir consolidadas categorias e estanques fronteiras epistemológicas. Mas este transgredir não é por transgredir, não é uma dessas

\footnotetext{
${ }^{23}$ A possibilidade de a partir de qualquer parte partir a explicar o todo é tratada no primeiro livro da "Doutrina do Ser" da Ciência da Lógica, iniciada com: Womit muß der Anfang der Wissenschaft gemacht werden? - Por onde tem de começar a Ciência?

${ }^{24}$ Simmel, GSG 6, p. 11.
} 
formas vazias favorecidas pelo elemento dinheiro que se encontrarão adiante na obra; antes pretende, num constante esforço, compreender o todo, para Simmel, o objecto da filosofia: «O mundo é-nos dado como uma soma de fragmentos e o esforço da filosofia é substituir a parte pelo todo» ${ }^{25}$. O dinheiro não é o objecto, o objectivo, o fim da Filosofia do Dinheiro: «nenhuma destas investigações pretende ser económica» ${ }^{26}$, diz-se também no prefácio.

Identificado o fim da Filosofia do Dinheiro, que não é o dinheiro mas o todo, o objecto da filosofia, falta-nos identificar o meio para tentar esse fim. O meio ou método de prosseguir a seu fim será fornecido pelo relativismo, pela epistemologia proposta no início da obra, terá de ser uma extensão, um prolongamento do relativismo.

O dinheiro é um meio, um material, um exemplo para a apresentação das relações entre os fenómenos mais superficiais, realísticos e fortuitos e os mais idealizados poderes da existência, as mais profundas correntes da vida individual e da história. ${ }^{27}$

O que aqui se enuncia, para além do dinheiro como meio a um fim, é a sua flexibilidade a tempo e espaço capaz de englobar desde o mais banal, real e íntimo ao mais profundo, ideal e abrangente. Na Filosofia do Dinheiro, o dinheiro descobrir-se-á materialização da relação, das relações históricas, sociais e individuais, por que vivemos, incluindo até a vida espiritual $^{28}$. Não sendo objecto da Filosofia do Dinheiro, o dinheiro é então a mais pura materialização do relativismo proposto por Simmel. É por ser o mais relativo, o melhor de todos os métodos relativistas possíveis, que o dinheiro é aqui método, mais que etimologicamente, caminho a um fim. Misturar filosofia com dinheiro maldito já representará para muitos suficiente transgressão. Mas assim fica entendido o porquê do Dinheiro, numa Filosofia do Dinheiro, função metodológica dados os seus relativos atributos, e o porquê da Filosofia na Filosofia do Dinheiro, dado ser esta uma obra filosófica com seu fim na totalidade.

${ }^{25}$ Simmel, GSG, 14, p. 32.

${ }^{26}$ Simmel, GSG 6, p. 11.

27 Simmel, GSG 6, p. 12.

${ }^{28}$ Não se pode admirar que a Filosofia do Dinheiro, não tratando economicamente o dinheiro, praticamente não exista para a ciência económica. Apesar de se aflorarem inconfessadas influências de Simmel na escola austríaca, esta questão é vincada em Von Flotow, Paschen e Schmidt, Johannes, Die Doppelrolle des Geldes bei Simmel und ihre Bedeutung für Ökonomie und Soziologie, in Rammstedt, Otthein e outros, Georg Simmels Philosophie des Geldes, Suhrkamp Taschenbuch Wissenschaft, Frankfurt am Main, 2003 pp. 80-82. 
Só se a forma do valor económico corresponder a uma forma do mundo pode no seu mais alto estádio de realização, atrás ou mesmo através da sua aparência, ajudar a interpretar a existência. ${ }^{29}$

Desfeitas assim as dúvidas quanto ao método e quanto ao fim, esta explícita divisão estende-se ao arrumar da própria obra em método e fim. Na primeira parte, analítica, o relativismo é meio de destrinçar, analisar, essas pré-condições sociais, psicológicas e metafísicas do dinheiro que o descobrirão como materialização do relativismo, como método, como meio; na segunda parte, sintética, o dinheiro, a descoberta materialização do relativismo, serve de método, de meio, para descobrir essa interdependência, essa ligação das coisas, a síntese desse todo.

Assim se explica a localização abrupta da proposta relativista na $\mathrm{Fi}$ losofia do Dinheiro, logo após a troca e o valor, e imediatamente antes de tratar propriamente do dinheiro, de o descobrir como "intrinsecamente" relacional, quase perfeita materialização do relativismo. Apresentado o relativismo, no final do primeiro capítulo ${ }^{30}$ da primeira parte (cada parte tem três capítulos) pode então seguir-se ao dinheiro. E, na lógica deste caminho, pode então agora o dinheiro ser introduzido como prolongamento do relativismo. Noutra formulação, é com esta justificação que começa a última secção do primeiro capítulo:

Antes de desenvolver o conceito de dinheiro como a incarnação e pura expressão do conceito de valor económico, é necessário mostrar o último como parte de uma visão teorética do mundo, nos termos da qual o significado filosófico do dinheiro pode ser entendido. ${ }^{31}$

A primeira parte é então um dar epistemologia para dela preparar um instrumento ou método a utilizar na segunda parte, verdadeiramente apontada ao fim da obra: relacionar coerentemente toda uma sucessão de variados e aparentemente desligados fenómenos. Ainda outra formulação: na primeira parte, a partir da análise de diversos fragmentos do todo, encontra a natureza relacional e relativa do dinheiro, para na segunda parte este instrumento, já "relativizado", servir a sintetizar o todo, uma realidade também ela relacional.

Uma parte procura tornar a essência do dinheiro inteligível a partir das conexões da vida em geral; reciprocamente, a outra parte procura fazer

${ }^{29}$ Simmel, GSG 6, p. 93.

${ }^{30}$ Simmel, GSG 6, p. 93-138.

31 Simmel, GSG 6, p. 93. 
a essência e organização da última inteligível a partir da eficácia do dinheiro. ${ }^{32}$

É como se Simmel, sem objecto mas com o instrumento entre-ligador no dinheiro, encontrasse uma ante-economia para se poder atrever a uma meta-economia, tornada verdadeira metafísica de abarcar a realidade. A arrumação simétrica da obra em $3+3$ capítulos, dado o fim da Filosofia do Dinheiro, dado o objecto da filosofia, coloca o seu centro gravítico na segunda parte. Mas a busca do método na primeira parte inocenta a obra de negligências metodológicas. Este dinheiro feito método filosófico liberta o dinheiro da esfera económica. O dinheiro maldito sobe agora a instrumento de religação abstracta do todo.

\section{O relativismo no dinheiro}

A vantagem do dinheiro está em, mais manifestamente que outra parcela da realidade, se revelar como interacção. Essa parcialidade de uma soma em dinheiro, esse tanto em dinheiro que é parte de uma soma total, um todo, já garante ao dinheiro a relatividade, a flexibilidade objectivadora das relações entre sujeitos, entre objectos, entre sujeitos e objectos. Poucas outras formas, além deste dinheiro subido a método, poderão plasmar a fluidez da sua epistemologia, qual já de si se propõe plasmar esses conteúdos fluidos da realidade. Aquela formulação relativista atrás tratada é perfeitamente materializada pelo dinheiro: assim, como a primeira parte da obra revelará o preço em dinheiro de um bem ou serviço como valendo relativamente a todos os outros bens e serviços, assim cada fenómeno vale, é recíproco, a todos os outros, cada conceito não o é sem se complementar de seus opostos e contradições. Assim como o dinheiro, a objectivação da troca que assim é super-objectivação do valor, imediatamente se adapta (em preços e valores) a interiorizar a mudança, a alteração das condições, assim o relativismo pretende dar essa adaptabilidade ao conhecimento face a uma alteração das condições, ou de um seu qualquer conteúdo. Estes atributos já o colocam como o melhor dos possíveis métodos relativistas. E o método é aqui mais que analógico. O dinheiro permite aqui uma multiplicação de posições, dimensões e perspectivas para depois reconstituir o tecido, essa indisciplinada inter-ligação dos fenómenos, invisível para a ciência mas intentável para a filosofia. Com o dinheiro, todos os conteúdos tratados na Filosofia do Dinheiro, seguem em modo relativo, empapados de relativismo. O dinheiro líquido, a não forma de se dar a toda a forma, adapta-se às permanentemente mutáveis formas da realidade. Imita o que o relativismo pretende imitar da realida-

${ }^{32}$ Simmel, GSG 6, p. 11. 
de, interiorizando até a contradição, numa interacção de contrários que, complementados, relacionados numa perspectiva, ajudam a vislumbrar a realidade. A forma da realidade a pulsar-lhe já de raiz, nessas pré-condições, é-lhe formalmente familiar. Naquela abertura avessa a sistematizações e fórmulas rígidas, pode então este método dinheiro seguir "a forma da realidade", espalhar-se por suas inumeráveis tonalidades, atirar-se, ainda que sempre incompletamente, a esse todo. Por enquanto.

Em obras posteriores, o relativismo irá, emancipar-se desta "forma", deste método dinheiro; mas mantendo estas suas características de complementaridade. Por isto, o conflito será socializante, forma privilegiada de criar ou modificar formações sociais; por isto, a sociedade precisará de harmonia e discórdia, associação e concorrência; por isto, a vida não sobreviverá sem a morte.

Pois aqui chegados à vida, pode mesmo fazer-se outra afirmação. Assim, como se viu, na Filosofia do Dinheiro, a epistemologia relacional já trai uma posterior ontologia relacional simmeliana, assim, na Filosofia do Dinheiro, o elemento ligador da diversidade de fenómenos e temas tratados, o dinheiro, já trai, embora limitadamente, muitos dos atributos da vida, categoria mais tardiamente desenvolvida e formalizada por Simmel. A vida será essa verdadeira forma, ou não forma porque infinitamente reformável, da realidade que aqui o dinheiro imita. Podem enumerar-se sucintamente as semelhanças entre este dinheiro e a vida, esses atributos imperfeitamente "vivos" do dinheiro.

Assim como a vida será a não forma de só sobreviver em formas vivas, de vida, será unidade e multiplicidade, limite e ilimitação, já aqui o dinheiro, a não forma de poder tomar qualquer forma, se poderá estender e dividir, concentrar em ponto, átomo, indivíduo ou instante. Assim como a vida será passado a levar já futuro, já aqui o dinheiro lhe segue, contabilisticamente e a crédito, essa flexibilidade temporal. Assim como a vida será fluxo com permanência, já aqui o dinheiro, como a epistemologia relativista pretende fazer, materializa uma nebulosa de inter-acções, materializa essa procurada estabilidade que se faz de contínua mudança ${ }^{33}$. Assim como a vida não o será sem ir, sem fluir, já aqui o dinheiro é actus purus, contínuo movimento ${ }^{34}$, relação que se faz de movimento e mudança.

Note-se, no entanto, que, como a Filosofia do Dinheiro já demonstra, o dinheiro imita mas imita imperfeitamente a vida. É que se o dinheiro se dá a toda a forma, a ligar tudo, é por precisamente tudo desligar. $\mathrm{O}$ dinheiro liga sujeitos, objectos e sujeitos com objectos, por precisamente os descartar de todos os seus atributos, os reduzir a uma única qualidade, a quantia e assim tornar tudo, toda a complexa e incomparável tonalidade

${ }^{33}$ Simmel, GSG 6, p. 715.

${ }^{34}$ Simmel, GSG 6, p. 714. 
do real comparável, uniformizada, igualizada - em monótona quantia. A grande objectivação, a grande abstracção quantificadora e uniformizadora, de que o dinheiro é causa e efeito (nesta prevalente reciprocidade, «in Simmel non esistono processi univoci o monocausali» ${ }^{35}$ ), segue com o dinheiro pelo direito, pela ciência, pela política, prossegue a instalar-se como única forma de conceber a realidade, invade mesmo as relações pessoais. Até toda a realidade nos vir em números - quantificada, igualizável, comparável. A grande objectivação, acarreta consigo um empobrecimento da vida expresso, por exemplo, naquelas figuras de alienação que, pondo como seu último fim o meio dos meios, o dinheiro, desfilam pela Filosofia do Dinheiro ${ }^{36}$.

Enquanto o dinheiro aplaina centripetamente tudo a si, igualiza em quantia toda a diversidade onde chega, a vida continuamente se expande e diversifica, centrifugamente enriquece a realidade de novas matizes, tonalidades, qualidades. Enquanto a vida evolui qualitativamente, o dinheiro, posto como fim último nas atrás referidas figuras de alienação, reflui tudo em quantia. Se efectivamente consegue chegar, como a vida, a toda a diversidade, tende a secá-la, tende a unificar tudo a $\mathrm{si}^{37}$. É isto que o homem experimenta quando todas as suas relações tendem a ser calculáveis e depois calculadas em quantia, objectiváveis e depois objectivadas por um interesse - em quantia. $\mathrm{O}$ dinheiro é uma simplificação imperfeita da vida a uma só dimensão quantitativa, que, posta fim último, tudo contamina à sua dimensão, nos aliena em não liberdade.

35 Remo Bodei, em Destini Personali, no capítulo “L'età della collonizzazzione delle differenze", Campi del Sapere / Feltrinelli, p. 174.

${ }^{36}$ Negativamente livres a todas as possibilidades, pelo dinheiro, não há nestas figuras qualquer criação, pôr ou positividade. Em todas, nessa liberdade negativa, o despojamento de seu fim. O avarento (Simmel, GSG 6, pp. 308-321) acumula, em dinheiro, possibilidade petrificada, nunca exercida. O esbanjador, (Simmel, GSG 6, pp. 321-328) viciado no prazer instante de obter objecto atrás de objecto, repete-o ao infinito. O asceta, a repudiar avaramente o dinheiro (Simmel, GSG 6, pp. 328-332), acumula, numa forma endinheirada, "capital espiritual". O blasé (Simmel, GSG 6, pp. 334-337), a fugir da degradante uniformização do dinheiro, procura repetida mas sempre insatisfatoriamente chegar onde ainda o dinheiro não chegou, um qualquer instante extremado de prazer.

${ }^{37}$ A individualidade, deixando que esta crescente uniformização a invada, penetre mesmo na sua intimidade, experimenta a própria negação da liberdade negativa que a abstracção e quantificação da vida juntamente com a flexibilidade do dinheiro lhe conferem. A grande objectivação, esse vergar das qualidades irregulares à mesma escala, é um tornar previsível, um igualizar pelo tempo; trai o mesmo esforço de eternização presente nas ganas de simetria dos Estados utópicos e despóticos (Simmel, GSG 6, p. 682). Esta regularização da irregularidade viva, esta uniformização empobrecedora da riqueza viva dos elementos individuais, aprisiona, indiferencia, mata. 
O dinheiro, mostrou-se, não é objecto, não é conteúdo, não é efeito na primeira e causa na segunda parte, da Filosofia do Dinheiro. Mas, nesta obra, onde uma parte metade a buscar o dinheiro é o avesso da outra a "usar" o dinheiro, o recente relativismo, afastado como vimos da sua tendencial conotação céptica, apoia-se no dinheiro. Se o conhecimento avança agora de galgar as barreiras ou feudos epistemológicos onde o tentavam espartilhar, mais este método dinheiro é adequada aplicação do relativismo. Enunciados os atributos do dinheiro, pode agora perceber-se porque quer Simmel, com o relativismo e seu prolongamento, interligar todo um mosaico de conteúdos ou exemplos a tentarem ligar e relacionar a realidade. Aliás, esta sua postura já claramente transporta um vislumbre do posterior Simmel ensaísta onde cada uma das muitas formas, cada fragmento à partida desfasado dá uma perspectiva do todo. Que o projecto anunciado no prefácio, «encontrar em todo o detalhe de vida a totalidade do seu sentido» ${ }^{38}$, exige agilidade, desprendimento e despreconceito - atributos do dinheiro - a liquidez simmeliana desdobra-se continuamente a explorar nas parcelas mais improváveis relações de reciprocidade, complementaridade, concorrência, afinal, as relações que fazem o dinheiro. Uma obra com tal diversidade de conteúdos, encontra a sua coerência numa epistemologia e num seu prolongamento metodológico, quais, em pura flexibilidade, buscam para cada particular as ligações a todos os outros particulares, ao todo.

Que o desvario de conteúdos desconcerte ao ponto de Frisby ver em Simmel uma quase aversão metodológica, esta só se poderá encontrar no que se usa convencionar como método. Sim, Simmel não impõe uma ordem ou método no sentido convencional. Mas, da forma ao conteúdo, a Filosofia do Dinheiro afasta qualquer sombra de descuido metodológico: divide-se em método e fim, em parte que analisa para obter o método, e em parte que sintetiza apontando a seu fim; especifica uma epistemologia; aplica-a metodologicamente dando coerência a essa escandalosa diversidade de conteúdos.

\section{O tipo filosófico entre o método dinheiro e a categoria vida}

Importa também referir que o incessante desdobramento de conteúdos e perspectivas na Filosofia do Dinheiro, justificado por sua epistemologia e seu método, revela uma perfeita coerência com a posterior concepção simmeliana dos diversos tipos filosóficos, perspectivas de penetrar na realidade. Agora, é ver como, entre o dinheiro como método e a ainda não formalizada categoria de vida, entre um Simmel já liberto do

${ }^{38}$ Simmel, GSG 6, p. 12. 
elemento ligador dinheiro mas ainda não formalmente apoiado na categoria vida, sobrevivem os pressupostos relativistas.

Em Os Problemas Fundamentais da Filosofia (Hauptprobleme der Philosophie) (1910), não são a lógica, o método, as circunstâncias pessoais não é um pensar universal objectivo e ou uma subjectividade indivídua que fazem a verdade de um filósofo. Esta vem-lhe peninsularmente de um terceiro elemento, o seu philosophischer Typus, tipo filosófico ${ }^{39}$. Nele prosseguem a relacionalidade, a interligação e o respeito pela peculiaridade da perspectiva direcionada ao todo, a livrarem a subjectividade de ser subjectiva. O tipo filosófico não se desliga nem numa pura subjectividade insular, pois o filósofo objectiva-se de viver num tipo humano mais geral, nem se perde numa pura objectividade continental. A sua objectividade está na sua concordância objectiva a sua personalidade, à expressão do seu tipo humano. A fidelidade não ao objecto, mas ao seu tipo filosófico, ao seu caminho, faz a verdade, objectiva, de um filósofo. Ele parte da sua parcialidade peninsular, parte da peculiaridade da sua forma típica, podemos acrescentar da sua perspectiva, para, fiel a seu tipo, visar uma imagem típica desse todo ligado por uma coerência nem indivídua ou subjectiva, nem universalmente objectiva, mas objectivamente individual.

Antes de prosseguir, note-se como esta forma de arrumação, que sobreviverá, por exemplo em sua Lei Individual ${ }^{40}$ (1913), este desdobrar repetidamente um terceiro elemento relacional e peninsular, livrado de se precipitar num dos pólos de um dualismo, será o próprio tipo filosófico de Simmel conceber o todo. E tal como Simmel se afasta de estafadas oposições duais, pois um pólo se não compreende sem o outro, de monismos contra dualismos, de passado contra presente, de objecto absoluto contra sujeito absoluto ${ }^{41}$, foge de métodos dogmaticamente a priori ou empíricos. A realidade é infinidade além de duas frias simplificações, não se deixa retalhar numa visão unidimensional, num arranjo bipolar. No ser, no tipo filosófico, na epistemologia, no dinheiro, na infinita e arrebatadora reciprocidade das ligações, Simmel eleva um terceiro, o terceiro elemento, ponte, pescoço, península entre o indivíduo e o todo.

O philosophischer Typus aplica em si a proposta, expressa no prefácio da Filosofia do Dinheiro, de relacionar hipoteticamente determinadas particularidades e conceitos abstractos ${ }^{42}$; é perfeitamente coerente com o relativismo, onde cada interpretação do todo, se fiel a suas tendências e para si mesmo objectiva ao seu fim, é, de sua peculiar perspectiva apontada ao

\footnotetext{
${ }^{39}$ Simmel, GSG 14, p. 28.

${ }^{40}$ Simmel, Das individuelle Gesetz, GSG 12, pp. 417-471.

${ }^{41}$ Simmel, GSG 6, p.110-113.

${ }^{42}$ Simmel, GSG 6, p. 10.
} 
todo, objectiva. Cada perspectiva contida na totalidade contínua, se pode somar a enriquecer de matizes essa riqueza jamais somável, o todo. E esta objectividade peculiar, perspectival, já de si objectiva, reforça-se mesmo em seu próprio relativismo, quando «elementos cujo conteúdo é subjectivo podem apresentar objectividade através da forma das suas mútuas relações.» ${ }^{43}$ Compreende-se agora melhor porque a epistemologia relativista garante que, sem fundamento, o conhecimento se suporte a si mesmo. As ligações entre os conteúdos do conhecimento garantem-lhes objectividade. A flexibilidade do método dinheiro, a ligar tantos e tão diferentes conteúdos, tonifica essa objectividade, já em cada tipo filosófico. A diversidade de conteúdos na Filosofia do Dinheiro, aparente ameaça à sua objectividade e aparente ausência de método, revela-se agora reforço de sua objectividade, quando, já se viu, tanto é causa como efeito de um método.

Com o dinheiro na sua Filosofia do Dinheiro, como o dinheiro nas suas obras posteriores, o tipo filosófico de Simmel, em sua flexibilidade endinheirada de se imiscuir nos outros tipos, bailará sobre os fenómenos, a ligá-los de todos a todos, explorando-lhes as ligações, esgotando-se nas suas perspectivas, para lhes encontrar a coerência. Tanto o relativismo de Simmel, como a consequente aplicação metódica e metodológica do seu relativismo na Filosofia do Dinheiro, já traem o seu tipo filosófico que, até à categoria vida, se manterá em variadas aplicações por toda a sua obra. Assim como sua metodologia não pode ser entendida em sentido convencional, também o seu legado o não pode ser. Naquela citação onde Simmel compara o seu legado a dinheiro líquido, não só reconhece em si, na fluidez e na diversidade de temas tratados na sua obra, as características do dinheiro, como, paradoxalmente para uma conclusão apressada, quer delas, da não rigidificação, da não permanência imortalizada, fazer seu legado.

\section{Referências bibliográficas}

Bodei, Remo, 2002, Destino Personali. L'età della collonizzazzione delle coscienze, Campi del Sapere / Feltrinelli, pp. 169-186.

Felizol Marques, Francisco, 2011, A Tragédia da Liberdade na Filosofia do Dinheiro de Georg Simmel, Diss. Mestrado, Faculdade de Letras da Universidade de Lisboa.

Von Flotow, Paschen e Schmidt, Johannes, 2003, „Die Doppelrolle des Geldes bei Simmel und ihre Bedeutung für Ökonomie und Soziologie", in Rammstedt, Otthein e outros, Georg Simmels Philosophie des Geldes, Suhrkamp Taschenbuch Wissenschaft, Frankfurt am Main, pp. 55-88.

Frisby, David, 2004, Introduction, in G. Simmel, Philosophy of Money, Routledge.

${ }^{43}$ Simmel, GSG 6, p. 113. 
Leger, François, 1989, La pensée de Georg Simmel. Contribution à l'histoire des idées en Allemagne au début du XXe siècle, Editions Kime.

Simmel, Georg, 1989, Philosophie des Geldes, Gesamtausgabe Band 6, Suhrkamp Taschenbuch Wissenschaft.

, 1995, Aufsätze und Abhandlungen 1901-1908, Gesamtausgabe Band 7, Suhrkamp Taschenbuch Wissenschaft.

, 2001, Aufsätze und Abhandlungen 1909-1918, Gesamtausgabe Band 12, Suhrkamp Taschenbuch Wissenschaft.

1996, Hauptprobleme der Philosophie; Philosophische Kultur, Gesamtausgabe Band 14, Suhrkamp taschenbuch wissenschaft.

\title{
RESUMO
}

Não sendo nem o objecto, nem o fim da Filosofia do Dinheiro, o dinheiro é antes a materialização e prolongamento de uma epistemologia proposta por Simmel. Esta, o relativismo, já com implicações ontológicas mais tarde desenvolvidas no seu conceito de individualidade, visa imunizar o conhecimento dos ataques cépticos. Fundando o conhecimento por o não fundar, por não o assentar em verdade improvada, substancial e petrificada, faz o conhecimento auto-sustentar-se ao colocar circunstancialmente em dependência recíproca e dinâmica todos os seus conteúdos. O dinheiro, a reciprocidade objectiva ligadora dos conteúdos mais improváveis, em seu contínuo movimento, já imperfeitamente com os atributos do que será a categoria simmeliana de vida, é então o método da Filosofia do Dinheiro explicando e viabilizando a variedade de temas aí tratados; é, mais que etimologicamente, o caminho (parte analítica) para o fim (parte sintética) da obra e da própria filosofia: compreender, pela interdependência das coisas, o todo.

Palavras-chave: Simmel, Relativismo, Dinheiro, Método, Vida

\begin{abstract}
Being neither the object nor the purpose of the Philosophy of Money, money is rather the materialization and prolongation of an epistemology proposed by Simmel. His relativism, already with ontological implications later developed in his concept of individuality, aims to immunize the knowledge against skeptical attacks. Founding knowledge for not found it, for not base it on a untried, substantial and petrified truth, makes it self-sustains, placing circumstantially in mutual and dynamic dependence all its contents. Money, the reciprocity objective linker of the most unlikely contents in its continuous movement, already imperfectly with the future attributes of the Simmelian life, is the Philosophy of Money's method. Money enables and explains the variety of topics treated there; it is, more than etymologically, the path (Analytical Part) to the purpose (Synthetic Part) of this book and even philosophy: understand, by the interdependence of things, the whole.
\end{abstract}

Keywords: Simmel, Relativism, Money, Method, Life 